\title{
Inverted Meckel's diverticulum associated with heterotopic pancreatic tissue causing intestinal obstruction: a case report
}

\author{
Mahmoud Kamel ${ }^{1^{*}}\left(\mathbb{0}\right.$, Hani Barsoum ${ }^{2}$, Suzan Talaat ${ }^{2}$ and Eman Mustafa ${ }^{2}$
}

\begin{abstract}
Background: Meckel's diverticulum is the most frequent congenital anomaly of the gastrointestinal tract. It can invert or invaginate into the small intestine lumen. It is usually associated with heterotopic tissue elements.

Case presentation: We present a case of inverted Meckel's diverticulum, clinically and radiologically diagnosed as intestinal obstruction due to intussusceptions. The diagnosis was suspected due to target sign shown on radiological examination. Pathologically, it was inverted Meckel's diverticulum obstructing the lumen in parallel plan mimicking the telescoping appearance, with heterotopic pancreatic tissue formed of exocrine and ductal components only.
\end{abstract}

Conclusions: Inverted Meckel's diverticulum may present by vague symptoms and may simulate other causes of intestinal obstruction.

Keywords: Meckel's diverticulum, Inverted Meckel, Heterotopic pancreas, Intestinal obstruction

\section{Background}

Meckel's diverticulum is the most frequent congenital anomaly of the gastrointestinal tract, and it occurs in approximately $2 \%$ of the general population. It results from incomplete atrophy of the omphalomesenteric (vitelline) duct (Levy and Hobbs 2004). It can invert or invaginate into the small intestine lumen. When occurring, the mesenteric fat surrounding the Meckel's diverticulum is pulled into the center and can progress into intussusception or bowel obstruction. These consequences could be very dangerous if they are not diagnosed and may lead to perforation, bowel necrosis, and sepsis (Levy and Hobbs 2004; Dujardin et al. 2002).

Meckel's diverticulum complications risk varies widely from 4 to $40 \%$ (Elsayes et al. (2007); Fink et al. 1995). The most common presentation in adults is bowel obstruction (Sagar et al. 2006). Heterotopic pancreatic tissue is a congenital anomaly in which pancreatic tissue is

\footnotetext{
*Correspondence: Newmak91@gmail.com

1 Pathology Department, Egyptian Fellowship, Cairo, Egypt

Full list of author information is available at the end of the article
}

anatomically separate from the main pancreatic gland with no vascular or duct continuity (Kung et al. 2010; Wei et al. 2011). The most frequent locations are the stomach (25.5\%), duodenum (27.7\%), proximal jejunum (15.9\%), Meckel diverticulum (5.3\%), and ileum (2.8\%) (Wei et al. 2011).

\section{Case presentation}

A 16-year-old Egyptian male patient was admitted to Ahmad Maher Teaching Hospital with acute intestinal obstruction. He also had history of many similar attacks but no history of gastrointestinal bleeding. Abdominal ultrasonography revealed target sign of intestinal intussusception. Total leucocytic count was $11 \times 109 / \mathrm{L}$. The patient underwent intestinal segment resection and endto-end anastomosis $60 \mathrm{~cm}$ proximal to ileo-cecal valve.

The received intestinal segment was $20 \mathrm{~cm}$ long and $3.5 \mathrm{~cm}$ wide. Serosa showed a dimple continuous with sausage-shaped projection measuring $6 \mathrm{~cm}$ long and $3 \mathrm{~cm}$ thick (Fig. 1). It was parallel to the long axis of the intestine and almost occluding the lumen. Cut section is 


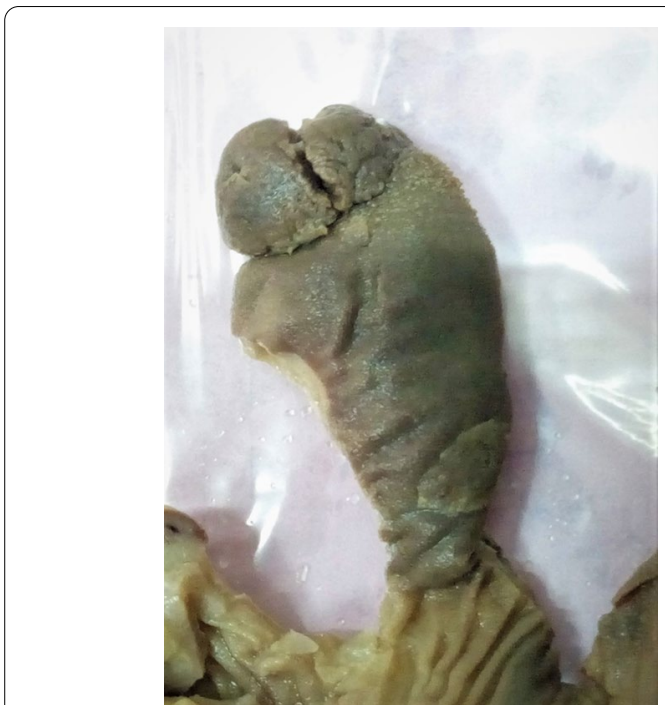

Fig. 1 Inverted Meckel's diverticulum protruding inside the lumen

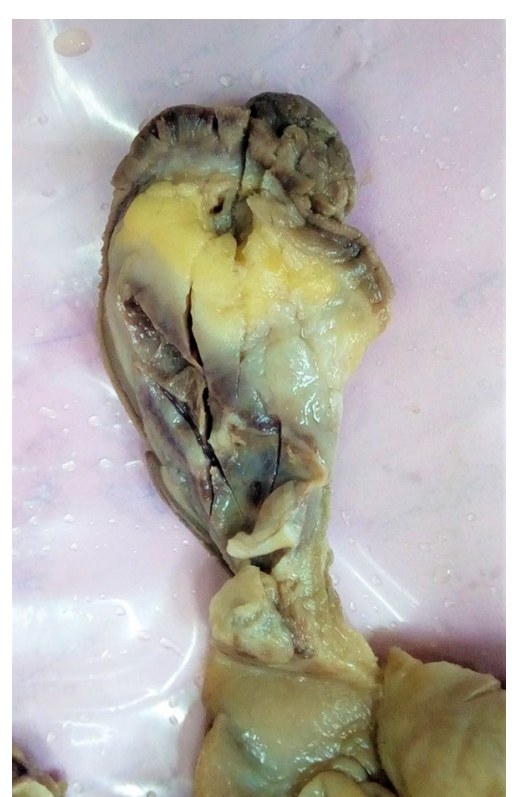

Fig. 2 Cut section of the diverticulum showing avulsion site near the tip representing the ectopic pancreatic tissue

heterogeneous showing firm brown nodule near the tip measuring $0.7 \mathrm{~cm}$ in diameter (Fig. 2).

Microscopically, a projection was covered by full-thickness small intestinal wall with variable degrees of inflammation and surface erosions. The firm nodule near the tip was formed of aggregates of serous acini (Fig. 3) surrounded by proliferating pyloric type glands with focal goblet cells showing no atypia and embedded within

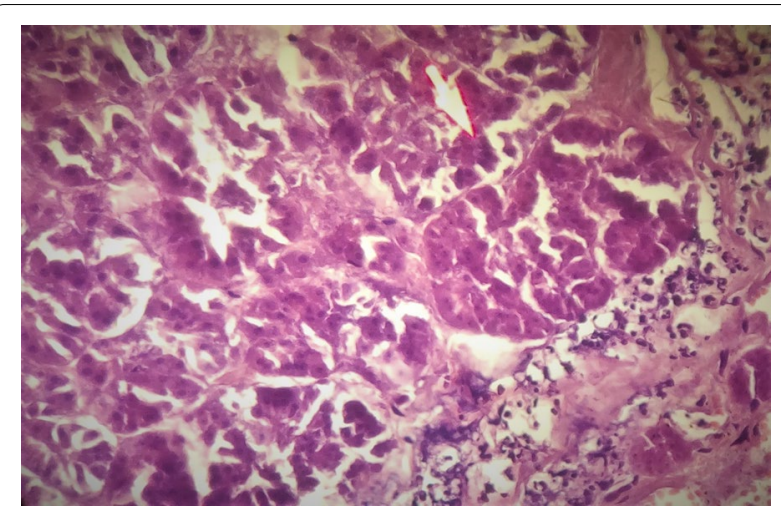

Fig. 3 Pancreatic acini (semi-autolyzed-high power-H\&E)

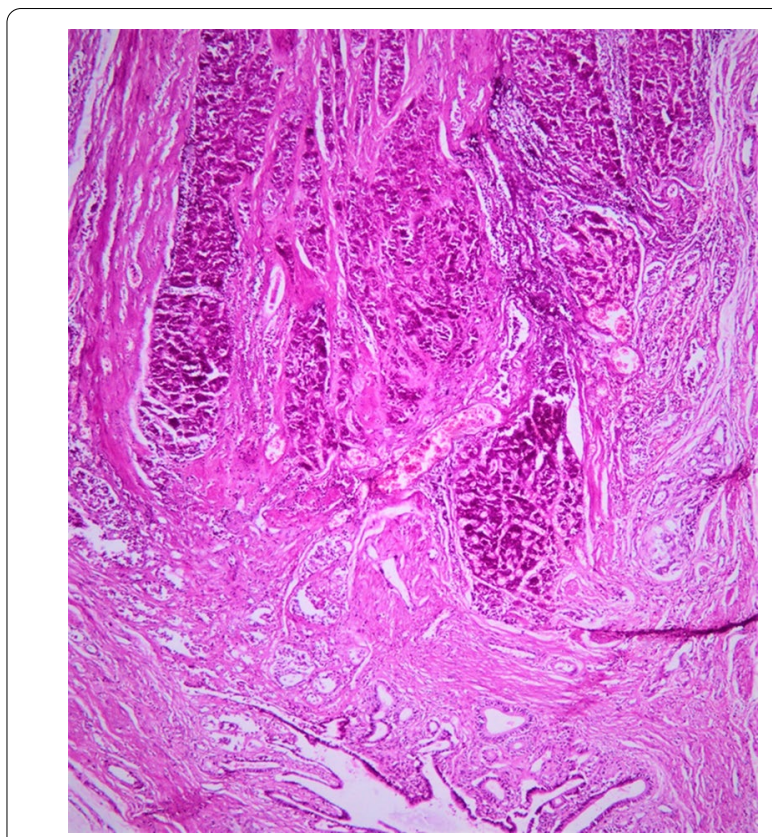

Fig. 4 Pancreatic acini and ducts (low power H\&E)

muscularis propria (Fig. 4). Immunohistochemistry was done and the acini were completely negative for chromogranin (Fig. 5) and both the acini and the ducts were positive for cytokeratin (Fig. 6), so it was diagnosed as heterotopic pancreatic tissue.

\section{Discussion}

Inverted Meckel's diverticulum is also presented clinically by lower gastrointestinal bleeding, chronic abdominal pain, or with symptoms and signs suggestive of small bowel obstruction. The most common age group is young adults unlike usual Meckel's diverticulum and generally presents as subacute or chronic 


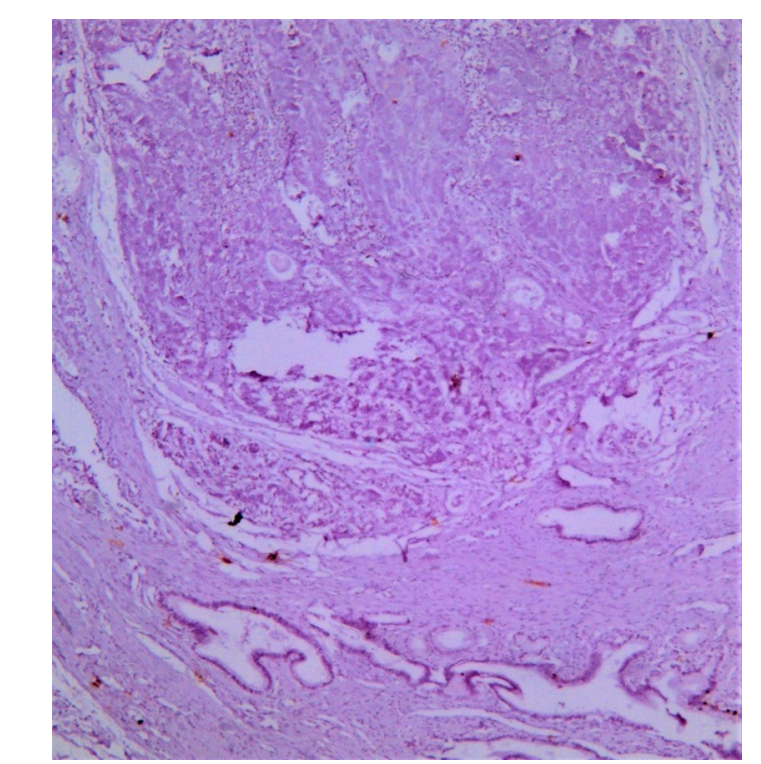

Fig. 5 Negative immunostain of chromogranin (low power)

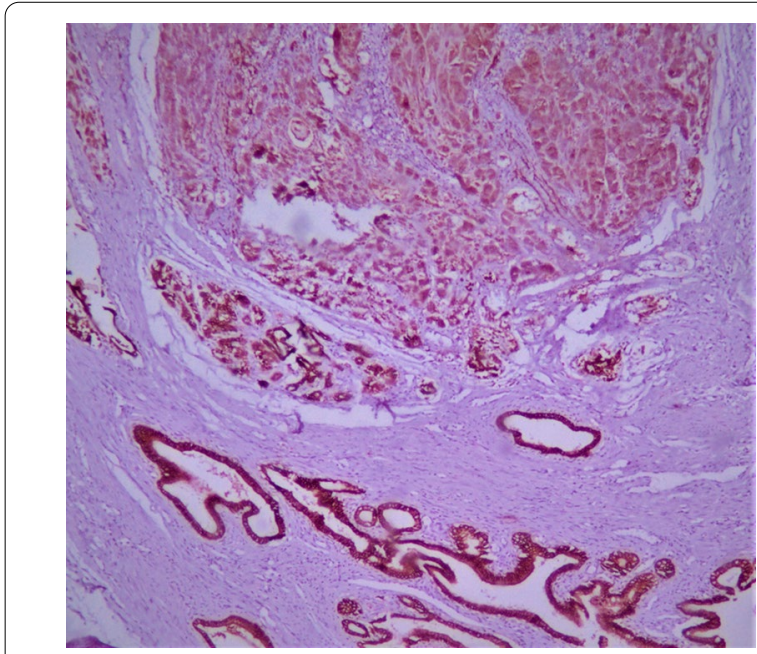

Fig. 6 Positive immunostain of pan cytokeratin (low power)

symptoms like abdominal pain or low-grade small intestinal obstruction (Pantongrag-Brown et al. 1996).

Our patient is young adult and has similar history except for the lower gastrointestinal bleeding. The absence of bleeding is probably due to non-existing heterotopic gastric tissue, whereby approximately $90 \%$ of Meckel's diverticula is manifested by bleeding due to contained gastric mucosa (Elsayes et al. 2007; Kusumoto et al. 1992). Another less common cause of pain and hemorrhage is acute inflammation of heterotopic pancreatic tissue (Zarand et al. 2011; Kopácová et al.
2010), but our case only showed non-inflamed heterotopic pancreas.

Preoperative ultrasonography revealed the target sign of intussusception (telescoping), when a loop of the small intestine with its mesentery invaginates into the lumen of the intestinal segment distal to it (Azar and Berger (1997)) However, the macroscopic examination showed only the inverted diverticulum inside and parallel to the intestinal wall resembling the telescoping appearance.

Pathology of the projection core showed mixed elements of fat and connective tissue representing the pulled mesentery to the center of the inverted diverticulum (Levy and Hobbs 2004; Dujardin et al. 2002). This filling of mesenteric fat is seen at the tip of the inverted sac as bulbous tip making a characteristic club-like appearance found in more than 90\% of cases (Gaisie et al. (1993)). And it was also seen in our case. It may also overlap with intestinal lipoma and can be differentiated by the presence of muscularis propria layer (Araki et al. 2012).

The detected pancreatic tissue is located in muscularis propria, and this location is detected in $8 \%$ of cases (Ulrych et al. (2015)). Heterotopic pancreatic tissue could be histologically divided into the following four types: (A) those comprising all cell types (total heterotopia), (B) those composed of ducts only (canalicular heterotopia), (C) those comprising acinar cells only (exocrine heterotopia), and (D) those composed of islet cells only (endocrine heterotopia) (Gaspar-Fuentes et al. 1973). Our case showed canalicular and exocrine components. The main differential diagnosis with our case is neuroendocrine tumor which is the most commonly developed neoplasm originating from Meckel's diverticulum (Levy and Hobbs 2004).We diagnosed pancreatic acini and excluded neuroendocrine tumor by chromogranin negativity.

\section{Conclusions}

We present a case of inverted Meckel's diverticulum, presented clinically with vague symptoms and radiologically diagnosed as intestinal obstruction due to intussusception. Pathologically, it was inverted Meckel's diverticulum with heterotopic pancreatic tissue. Usually, it is associated with heterotopic elements and should be diagnosed thoroughly.

\section{Acknowledgements}

The author would like to acknowledge the colleagues and technicians for supporting and facilitating this work and would like to thank reviewers for their in-depth comments that improved the manuscript.

\section{Author contributions}

MK described the macroscopic specimen and wrote the manuscript. HB recommended the manuscript and the immunohistochemistry panel. ST and EM participated in its design and coordination and helped to draft the manuscript. All authors read and approved the final manuscript. 


\section{Funding}

The authors did not receive any financial support from anybody.

\section{Availability of supporting data}

All material are available.

\section{Ethics approval and consent to participate}

Human tissue, approved by Ahmed Maher teaching hospital.

\section{Consent for publication}

Written informed consent to publish this information was obtained from the parent.

\section{Competing interests}

The authors declare that they have no financial or nonfinancial competing interests.

\section{Author details}

${ }^{1}$ Pathology Department, Egyptian Fellowship, Cairo, Egypt. ${ }^{2}$ Pathology Department, Ahmad Maher Teaching Hospital, Cairo, Egypt.

Received: 16 April 2020 Accepted: 6 January 2021

Published online: 15 January 2021

\section{References}

Araki A, Tsuchiya K, Oshima S et al (2012) Endoscopic ultrasound with doubleballoon endoscopy for the diagnosis of inverted Meckel's diverticulum: a case report. J Med Case Rep 6:328

Azar T, Berger DL (1997) Adult intussusception. Ann Surg 226:134-138

Dujardin M, de Beeck BO, Osteaux M (2002) Inverted Meckel's diverticulum as a leading point for ileoileal intussusception in an adult: case report. Abdom Imaging 27:563-565

Elsayes KM, Menias CO, Harvin HJ et al (2007) Imaging manifestations of Meckel's diverticulum. AJR Am J Roentgenol 189:81-88
Fink AM, Alexopoulou E, Carty H (1995) Bleeding Meckel's diverticulum in infancy: unusual scintigraphic and ultrasound appearances. Pediatr Radiol 25:155-156

Gaisie G, Kent C, Klein L et al (1993) Radiographic characteristics of isolated invaginated Meckel's diverticulum. Pediatr Radiol 23:355-356

Gaspar-Fuentes A, Campos-Tarrech JM, Fernandez-Burgui JL et al (1973) Pancreatic ectopias. Rev Esp Enferm Apar Dig 39:255-268

Kopácová M, Vykouril L, Vacek Z et al (2010) Inverted Meckel's diverticulum with ectopic pancreatic tissue as a source of severe gastrointestinal bleeding. J Gastrointest Surg 14:578-581

Kung JW, Brown A, Kruskal JB et al (2010) Heterotopic pancreas: typical and atypical imaging findings. Clin Radiol 65(5):403-407

Kusumoto H, Yoshida M, Takahashi I et al (1992) Complications and diagnosis of Meckel's diverticulum in 776 patients. Am J Surg 164:382-383

Levy AD, Hobbs CM (2004) From the archives of the AFIP. Meckel diverticulum: radiologic features with pathologic correlation. Radiographics 24:565-587

Pantongrag-Brown L, Levine MS, Buetow PC et al (1996) Meckel's enteroliths: clinical, radiologic, and pathologic findings. AJR Am J Roentgenol 167:1447-1450

Sagar J, Kumar V, Shah DK (2006) Meckel's diverticulum: a systematic review. J R Soc Med 99:501-505

Ulrych J, Fryba V, Skalova H et al (2015) Premalignant and malignant lesions of the heterotopic pancreas in the esophagus: a case report and review of the literature. J Gastrointestin Liver Dis 24(2):235-239

Wei R, Wang QB, Chen QH et al (2011) Upper gastrointestinal tract heterotopic pancreas: findings from CT and endoscopic imaging with histopathologic correlation. Clin Imaging 35(5):353-359

Zarand A, Bajtai A, Baranyai Z et al (2011) Inflammation of ectopic pancreatic tissue in a Meckel's diverticulum causing acute abdominal symptoms: a case report and review of the literature. Int J Surg Pathol 19:359-363

\section{Publisher's Note}

Springer Nature remains neutral with regard to jurisdictional claims in published maps and institutional affiliations.

\section{Submit your manuscript to a SpringerOpen ${ }^{\circ}$ journal and benefit from:}

- Convenient online submission

- Rigorous peer review

- Open access: articles freely available online

- High visibility within the field

- Retaining the copyright to your article

Submit your next manuscript at $\boldsymbol{\nabla}$ springeropen.com 